Check for updates

Cite this: Mater. Adv., 2020, 1,1285

Received 26th May 2020,

Accepted 1st July 2020

DOI: 10.1039/d0ma00348d

rsc.li/materials-advances

\title{
Transition metal-tetracyanoquinodimethane monolayers as single-atom catalysts for the electrocatalytic nitrogen reduction reaction $\dagger$
}

\author{
Yiran Ying, (D) ${ }^{a}$ Ke Fan, (D) ${ }^{a}$ Xin Luo, (D) $*^{b}$ Jinli Qiao (D) ${ }^{c}$ and Haitao Huang (D) $\star^{a}$
}

\begin{abstract}
Converting earth-abundant nitrogen into value-added chemical ammonia is a significant yet challenging topic. The electrocatalytic nitrogen reduction reaction (NRR), compared with the conventional HaberBosch process, is an energy-saving and environmentally friendly approach. Finding electrocatalysts which can activate nitrogen effectively and exhibit high selectivity and stability for the electrocatalytic NRR is a major task. Single-atom catalysts can act as a good solution. In this work, by means of firstprinciples density functional theory, molecular dynamics calculations, and a two-step screening process, we have studied 17 transition metal single atoms supported on tetracyanoquinodimethane monolayers (TM-TCNQ), and among them, Sc-TCNQ and Ti-TCNQ are found to be excellent candidates for NRR electrocatalysts. $\mathrm{N}_{2}$ adsorption and activation are effective due to the 'acceptance-donation' mechanism and suitable electronic structure of TM-TCNQ. The Gibbs free energy diagram shows that SC-TCNQ and Ti-TCNQ exhibit a low NRR overpotential of 0.33 and $0.22 \mathrm{~V}$, respectively, through an enzymaticconsecutive mixed pathway. In addition, the selectivity of the NRR over the HER and stability of the Sc-/ Ti-TCNQ monolayers are also validated. This work opens a new avenue for designing novel single-atom catalysts for the NRR as well as other catalytic applications.
\end{abstract}

\section{Introduction}

Ammonia $\left(\mathrm{NH}_{3}\right)$ is an indispensable chemical in industry and agriculture because it is not only a precursor to the production of many types of fertilizers, chemicals, and pharmaceuticals, but also a clean, carbon-free energy carrier whose combustion products (nitrogen and water) are all environmentally benign. ${ }^{1-3}$ Nitrogen fixation, converting nitrogen $\left(\mathrm{N}_{2}\right)$ - the most abundant gas in Earth's atmosphere which cannot be directly utilized by human beings-into value-added chemical ammonia, is undeniably an urgent topic ever since human industrialization. According to Mineral Commodity Summaries from US Geological Survey, about 170 million tons of ammonia in total were produced globally in 2018. ${ }^{4} \mathrm{~A}$ major challenge in nitrogen fixation is to

\footnotetext{
${ }^{a}$ Department of Applied Physics, The Hong Kong Polytechnic University, Hung Hom, Kowloon, Hong Kong, P. R. China. E-mail: aphhuang@polyu.edu.hk

${ }^{b}$ State Key Laboratory of Optoelectronic Materials and Technologies, Centre for Physical Mechanics and Biophysics, School of Physics, Sun Yat-sen University, Guangzhou, Guangdong Province, 510275, P. R. China.

E-mail:luox77@mail.sysu.edu.cn

${ }^{c}$ College of Environmental Science and Engineering, State Key Laboratory for Modification of Chemical Fibers and Polymer Materials, Donghua University, Shanghai 201620, China

$\dagger$ Electronic supplementary information (ESI) available. See DOI: 10.1039/ d0ma00348d
}

break the chemically inert $\mathrm{N} \equiv \mathrm{N}$ triple bond, for which, the conventional nitrogen fixation approach-Haber-Bosch (H-B) process requires high temperature and pressure and is highly energy demanding, accounting for around $2 \%$ of global supply of energy. ${ }^{5-10}$ Besides, the $\mathrm{H}-\mathrm{B}$ process needs a large plant infrastructure and may raise environmental issues such as emission of carbon dioxide, which takes up about $1 \%$ of total greenhouse gas emission. ${ }^{10,11}$

The electrocatalytic nitrogen reduction reaction (NRR, $\mathrm{N}_{2}+$ $6 \mathrm{H}^{+}+6 \mathrm{e}^{-} \rightarrow 2 \mathrm{NH}_{3}$ ), inspired by the biological NRR with nitrogenase enzymes, can be a promising alternative for the $\mathrm{H}-\mathrm{B}$ process because the reaction can take place under ambient conditions. $^{7,11,12}$ Discovering electrocatalysts for the NRR with high activity and selectivity is a significant task for both fundamental research and industrial applications. ${ }^{13}$ The past decade has witnessed the efforts in investigating pure metals,${ }^{13,14}$ metal oxides,${ }^{15}$ metal nitrides,${ }^{16}$ metal carbides,${ }^{17}$ and metal phosphides ${ }^{18}$ as NRR electrocatalysts by means of density functional theory (DFT) calculations. However, the relatively low utilization percentage of active materials and high cost of these metal-based electrocatalysts hinder their experimental realization.

Recently, another group of catalysts, single-atom catalysts (SACs), have attracted the attention from researchers. SACs, which are defined as isolated atoms anchored on substrates, 
exhibit remarkable catalytic performance and relatively low cost because of the full utilization of active metal atoms, high selectivity, and stability. ${ }^{19}$ Aside from these features, transition metal (TM) based SACs can be very effective especially for the NRR because the d electrons of the single metal supported on a substrate are more active than those in the aggregated form, and are more liable to activate the $\mathrm{N} \equiv \mathrm{N}$ triple bond. Two-dimensional materials, due to their large surface area and unique physical, chemical, and electronic properties, ${ }^{20-24}$ have become an important platform for the design of SACs for the NRR. DFT calculations predict that transition metal (TM) atoms embedded in two-dimensional boron nitride, ${ }^{25}$ nitrogen-doped graphene, ${ }^{26,27}$ graphitic carbon nitride, ${ }^{28-30}$ and transition metal dichalcogenides ${ }^{31,32}$ are outstanding SACs for the NRR. Nevertheless, in experiments, examples of SACs for the NRR are scarce and only limited to single transition metals (TMs) supported on nitrogen-doped carbon ${ }^{33-36}$ and more efforts into this burgeoning area are still needed.

The potential of metal-organic frameworks (MOFs) to form SACs due to their tunable geometric structure and large surface area has been recently demonstrated..$^{37-39}$ As an outstanding electron acceptor, 7,7,8,8-tetracyanoquinodimethane (TCNQ) can serve as a substrate in the formation of SACs. Many transition metals supported on TCNQ structures have been synthesized in experiments with their electronic and magnetic properties widely studied. ${ }^{40-42}$ For electrocatalytic applications, different TM-TCNQ monolayers have been predicted by DFT calculations to be promising electrocatalysts for oxygen evolution and reduction, ${ }^{4,44} \mathrm{CO}$ oxidation, ${ }^{45}$ and $\mathrm{CO}_{2}$ reduction reactions. ${ }^{46}$ However, the application of TM-TCNQ as an electrocatalyst for the NRR has not been investigated theoretically or experimentally.

Based on the information given above, in this work, we use DFT calculations to search for potential candidates as electrocatalysts for the NRR in TM-TCNQ monolayers by screening 17 TM elements which are common on the Earth (Sc-Zn, Mo, $\mathrm{Ru}-\mathrm{Pd}, \mathrm{Ag}, \mathrm{Pt}$, and $\mathrm{Au}$ ). Gibbs free energy calculations are conducted to evaluate the NRR performance of the selected samples. The stability and NRR selectivity of these SACs are also checked.

\section{Computational methods}

All spin-polarized DFT calculations were performed by employing the projector-augmented wave method implemented in the Vienna $a b$ initio Simulation Package (VASP). ${ }^{4,48}$ PerdewBurke-Ernzerhof (PBE) flavor of the generalized gradient approximation $^{49}$ was chosen as the exchange-correlation functional. For the consideration of van der Waals interactions, Grimme's DFT-D3 semiempirical scheme was applied. ${ }^{50}$ The kinetic energy cut-off was set as $400 \mathrm{eV}$ and the first Brillouin zone was sampled with Gamma-centered $7 \times 5 \times 1$ MonkhorstPack meshes. Both cell and ionic degrees of freedom of all structures were allowed to relax until convergence criteria $\left(10^{-5} \mathrm{eV}\right.$ for energy and $0.02 \mathrm{eV} \AA^{-1}$ for force) were satisfied.
A vacuum layer with a thickness larger than $20 \AA$ was used to avoid spurious interactions between adjacent cells. Grid-based Bader charge analysis ${ }^{51}$ was used to calculate the charge transfer. AIMD simulations were performed in the NVT ensemble with a Nosé-Hoover thermostat implemented in VASP. ${ }^{52,53}$ For the calculation of kinetic energy barriers, the climbing image nudged elastic band method ${ }^{54}$ was used. Structures were visualized with the VESTA package ${ }^{55}$ and VASPKIT code $^{56}$ was used for processing the calculation results from VASP.

NRR was considered as a six net coupled proton and electron transfer (CPET) process and one coupled proton and electron were transferred from the solution to the surface of the electrocatalyst for each step. The Gibbs free energy was calculated using the following formula: ${ }^{57}$

$$
\Delta G=\Delta E_{\mathrm{DFT}}+\Delta E_{\mathrm{ZPE}}-T \Delta S+\Delta G_{\mathrm{pH}}
$$

where $\Delta E_{\mathrm{DFT}}, \Delta E_{\mathrm{ZPE}}, T \Delta S$, and $\Delta G_{\mathrm{pH}}$ represent the difference of DFT-calculated adsorption energy, zero point energy (ZPE), entropic contribution, and free energy correction of $\mathrm{pH}$ in each reaction step. The conventional hydrogen electrode $(\mathrm{CHE})$ model to calculate the Gibbs free energy of $\left(\mathrm{H}^{+}+\mathrm{e}^{-}\right)$is ${ }^{58}$

$$
G\left(\mathrm{H}^{+}+\mathrm{e}^{-}\right)=0.5 G\left(\mathrm{H}_{2}\right)-\mathrm{e} U
$$

where $U$ represents the electrode potential relative to the CHE. $\mathrm{ZPE}$ and entropic contribution were calculated from vibrational frequencies $\omega_{i}::^{17,59,60}$

$$
\begin{gathered}
E_{\mathrm{ZPE}}=\frac{1}{2} \sum_{i} \hbar \omega_{i} \\
\mathrm{TS}=\mathrm{RT}\left\{\sum_{i} \frac{\frac{\hbar \omega_{i}}{k_{\mathrm{B}} T}}{\exp \left(\frac{\hbar \omega_{i}}{k_{\mathrm{B}} T}\right)-1}-\sum_{i} \ln \left[1-\exp \left(-\frac{\hbar \omega_{i}}{k_{\mathrm{B}} T}\right)\right]\right\} .
\end{gathered}
$$

where $k_{\mathrm{B}}$ and $R$ represent the Boltzmann constant and gas constant, respectively.

\section{Results and discussion}

\subsection{Screening TM-TCNQ monolayers for the NRR and $\mathbf{N}_{2}$ activation}

The structures of TM-TCNQ are modelled by a $2 \times 2$ supercell with twelve carbon atoms, four nitrogen atoms, four hydrogen atoms, and one TM atom. A prototypical DFT-optimized structure of TM-TCNQ-Sc-TCNQ is shown in Fig. 1. The lattice constants for $\mathrm{TM}=\mathrm{Sc}, \mathrm{Ti}, \mathrm{V}, \mathrm{Cr}, \mathrm{Mn}, \mathrm{Fe}, \mathrm{Co}, \mathrm{Ni}, \mathrm{Cu}, \mathrm{Zn}$, Mo, Ru, Rh, Pd, Ag, Pt, and Au are listed in Table S1 (ESI $\dagger$ ). All TM-TCNQ structures exhibit planar structures and each TM atom coordinates with four nitrogen atoms from TCNQ. From Bader charge analysis, in Sc-TCNQ, Ti-TCNQ, and V-TCNQ, the TM atoms transfer $1.87 \mathrm{e}^{-}, 1.80 \mathrm{e}^{-}$, and $1.46 \mathrm{e}^{-}$to the TCNQ substrate, respectively, indicating that TCNQ can accept electrons from TM atoms. We further calculate the electron localized function (ELF) and show the contour plot in Fig. 1a. The ELF values close to 0.5 and 1 suggest the metal bond (delocalized electrons) and covalent bond (localized electrons), 
(a)

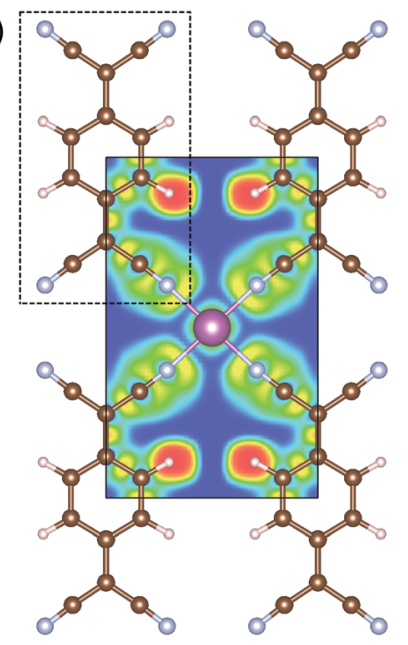

(b)

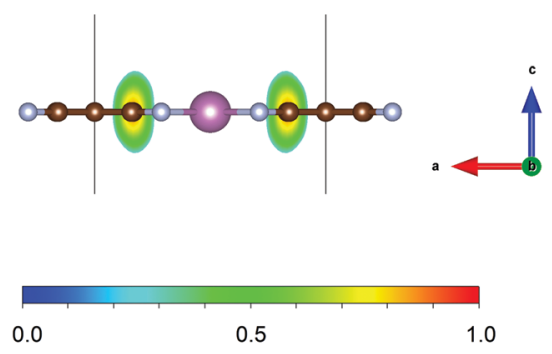

TM

$\odot \mathrm{C}$

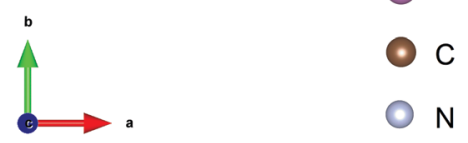

Fig. 1 (a) Top and (b) side view of the optimized structure of Sc-TCNQ and the corresponding electron localized function contour map. Sc, C, N, and H atoms are represented in purple, brown, cyan, and pale pink, respectively. Black solid line denotes the cell boundary of Sc-TCNQ, and the dashed line denotes the TCNQ molecule. Isodensity values for ELF map are shown below Fig. 1b.

respectively, while ELF values smaller than 0.5 represent the ionic bond. ${ }^{61,62}$ From Fig. 1a, we can conclude that ionic bonds form between Sc and adjacent $\mathrm{N}$ atoms. Inside the TCNQ substrate, on the other hand, covalent bonds form between atoms.

The $\mathrm{N}_{2}$ adsorption and activation of the $\mathrm{N} \equiv \mathrm{N}$ triple bond is the first and vital step for the NRR. ${ }^{12,13}$ In this context, before proceeding to study the NRR reaction pathways, we first examine the $\mathrm{N}_{2}$ adsorption on TM-TCNQ. Two adsorption patterns of $\mathrm{N}_{2}$ are considered-side-on configuration with both $\mathrm{N}$ atoms binding with the TM atom (active site for the NRR), and end-on configuration with one of the $\mathrm{N}$ atoms binding with the TM atom (Fig. S1, ESI†). Each configuration could lead to different NRR reaction pathways. From pioneering theoretical investigations, it can be deduced that the NRR is a complicated process and several pathways have been concluded. ${ }^{25,27,63}$ For the end-on configuration, distal, alternating, and their mixed mechanisms are possible (Fig. S2, ESI†). For the side-on configuration, enzymatic, consecutive, and their mixed mechanisms are proposed (Fig. 2). As a result, screening the $\mathrm{N}_{2}$ adsorption ability and configuration on TM-TCNQ for each TM is our top priority.
$\mathrm{N}_{2}$ adsorption energy values $E_{\text {ad }}$, defined as $E_{\text {ad }}=$ $E\left(\mathrm{TM}-\mathrm{TCNQ}+\mathrm{N}_{2}\right)-E(\mathrm{TM}-\mathrm{TCNQ})-E\left(\mathrm{~N}_{2}\right)$, are calculated and summarized in Table S2 (ESI $\dagger$ ) and Fig. 3a for both side-on and end-on patterns on TM-TCNQ. For effective activation of $\mathrm{N}_{2}, E_{\text {ad }}$ should be negative enough $(<-0.5 \mathrm{eV})$ to ensure the energetically favorable $\mathrm{N}_{2}$ chemisorption. ${ }^{27}$ From Fig. 3(a), five cases of end-on configuration (Sc-TCNQ, Ti-TCNQ, V-TCNQ, Cr-TCNQ, and Mn-TCNQ), and one case of side-on configuration (Ti-TCNQ) are selected from a total of 34 structures. Nevertheless, three other structures, i.e. Sc-TCNQ and V-TCNQ with a side-on $\mathrm{N}_{2}$ adsorption pattern and Fe-TCNQ with an endon $\mathrm{N}_{2}$ adsorption pattern can also ensure the chemisorption by forming TM-N bonds with a bond length smaller than $2.4 \AA$ (Fig. S1a and S3a, b, ESI $\dagger$ ), even though they exhibit slightly larger $E_{\text {ad }}$ values than $-0.5 \mathrm{eV}$. On the other hand, the rest of the structures such as Au-TCNQ (Fig. S3c and d, ESI $\dagger$ ) cannot form $\mathrm{TM}-\mathrm{N}$ chemical bonds because of the large distance between TM and $\mathrm{N}$ atoms, and therefore $\mathrm{N}_{2}$ molecules cannot be effectively activated. Thus, they are not considered in the following calculations.

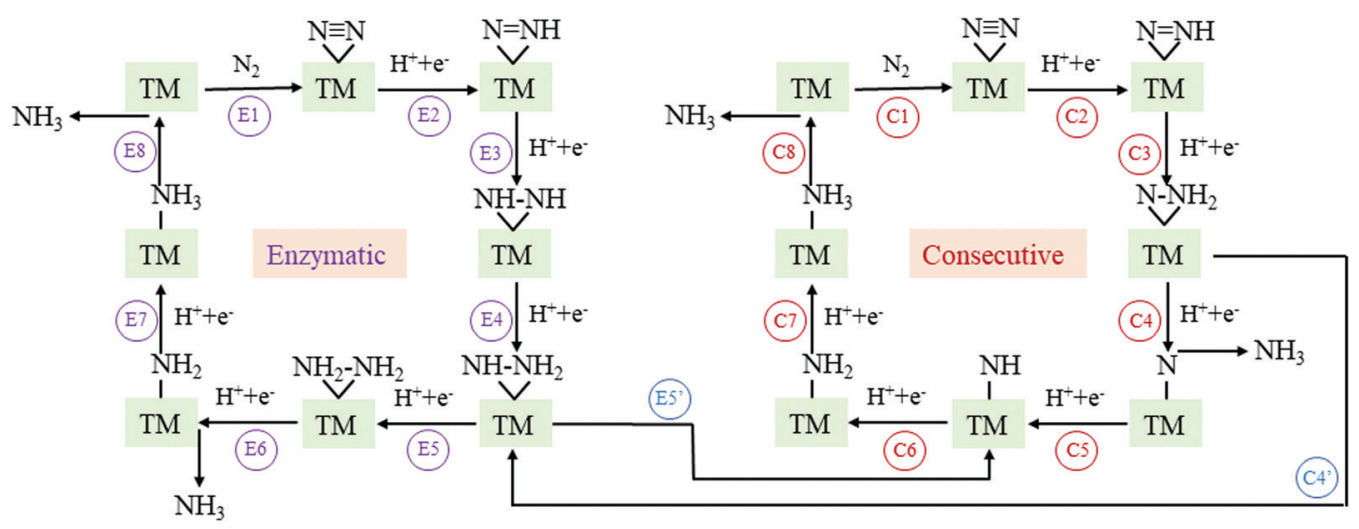

Fig. 2 Schematic illustration of enzymatic, consecutive, and their mixed mechanism for the NRR on TM-TCNQ. TM denotes the transition metal atom (active site) in the figures. 
(a)
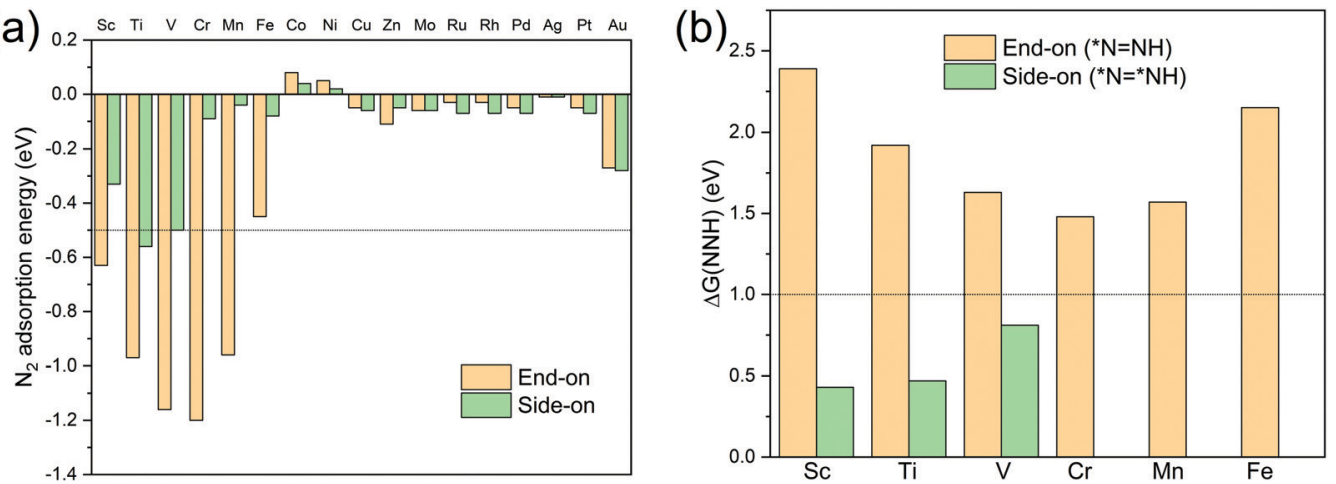

Fig. 3 The two-step screening strategy for TM-TCNQ electrocatalysts for the NRR. (a) Calculated $\mathrm{N}_{2}$ adsorption energy for both end-on and side-on configurations on TM-TCNQ (TM $=\mathrm{Sc}-\mathrm{Zn}, \mathrm{Mo}, \mathrm{Ru}-\mathrm{Pd}, \mathrm{Ag}, \mathrm{Pt}$, and $\mathrm{Au}$ ), and (b) Gibbs free energy change values $\Delta G(\mathrm{NNH})$ of $* N \equiv N+\left(\mathrm{H}^{+}+\mathrm{e}^{-}\right) \rightarrow$ ${ }^{*} \mathrm{~N}=\mathrm{NH}$ for SC-, Ti-, $\mathrm{V}-, \mathrm{Cr}-, \mathrm{Mn}-, \mathrm{Fe}-\mathrm{TCNQ}$, and ${ }^{*} \mathrm{~N} \equiv \mathrm{N}^{*}+\left(\mathrm{H}^{+}+\mathrm{e}^{-}\right) \rightarrow{ }^{*} \mathrm{~N}=\mathrm{NH}^{*}$ for Sc-, Ti-, $\mathrm{V}-\mathrm{TCNQ}$.

To further screen the remaining nine structures for the NRR, we calculate the Gibbs free energy change for ${ }^{*} \mathrm{~N} \equiv \mathrm{N}+$ $\left(\mathrm{H}^{+}+\mathrm{e}^{-}\right) \rightarrow{ }^{*} \mathrm{~N}=\mathrm{NH}$ (end-on) and ${ }^{*} \mathrm{~N} \equiv \mathrm{N}^{*}+\left(\mathrm{H}^{+}+\mathrm{e}^{-}\right) \rightarrow$ ${ }^{*} \mathrm{~N}=\mathrm{NH}^{*}$ (side-on) (here, ${ }^{*}$ denotes the active sites for the NRR), because these steps (the first hydrogenation step in Fig. S2, ESI $\dagger$ and Fig. 2, respectively) are proven to be the potential limiting step (PLS) for the NRR in many TM-based SACs. ${ }^{26,64-67}$ To consider the energy barrier values for transforming from end-on configuration ${ }^{*} \mathrm{~N} \equiv \mathrm{N}$ to side-on configuration ${ }^{*} \mathrm{~N} \equiv \mathrm{N}^{*}$, we perform CI-NEB calculations to identify the minimum energy path for the transformation on Sc- and Ti-TCNQ as examples. Results (Fig. S4, ESI $\dagger$ ) show that the transformation energy barrier values are 0.42 and $0.55 \mathrm{eV}$ for Sc- and Ti-TCNQ, respectively, indicating that our two-step screening process is valid considering the non-simultaneous reaction intermediates involved in the two steps. Fig. $3 \mathrm{~b}$ indicate that for all six end-on structures, the corresponding Gibbs free energy change values $\Delta G(\mathrm{NNH})$ are larger than $1.0 \mathrm{eV}$. These values are much higher than most of the reported SACs for the NRR and will lead to high overpotential and mediocre
NRR performance. On the other hand, for Sc-, Ti-, and V-TCNQ, the side-on $\mathrm{N}_{2}$ adsorption patterns can result in $\Delta G(\mathrm{NNH})$ values smaller than $1.0 \mathrm{eV}$. For $\mathrm{N}_{2}$ adsorption, the difference in energy between side-on and end-on configuration is $0.30,0.39$, and $0.66 \mathrm{eV}$ for Sc-, Ti-, and V-TCNQ, respectively (Fig. 3a), far smaller than the energy difference between end-on and side-on $\mathrm{N}_{2}$ hydrogenation $\left({ }^{*} \mathrm{~N} \equiv \mathrm{N} \rightarrow{ }^{*} \mathrm{~N}=\mathrm{NH}\right.$ (end-on) and ${ }^{*} \mathrm{~N} \equiv \mathrm{N}^{*} \rightarrow{ }^{*} \mathrm{~N}=\mathrm{NH}^{*}$ (side-on)), which are 1.96, 1.45, and $0.82 \mathrm{eV}$ (Fig. 3b). To conclude, after the two-step screening process shown above, we have identified these 3 structures (Sc-, Ti-, and V-TCNQ with side-on consideration) out of the 34 for further investigations because they are more energetically favorable in the two sequential steps.

The electronic structure is an important factor for evaluating the $\mathrm{N}_{2}$ activation on NRR catalysts. Using Sc-TCNQ as an example, we find that the density of states (DOSs) of pure Sc-TCNQ (Fig. 4a) clearly show the metallic character, which facilitates fast charge transfer and is beneficial to the potential electrocatalytic process. The DOS plot for $\mathrm{N}_{2}$ in the gas phase is shown in Fig. 4b, where the lowest unoccupied molecular

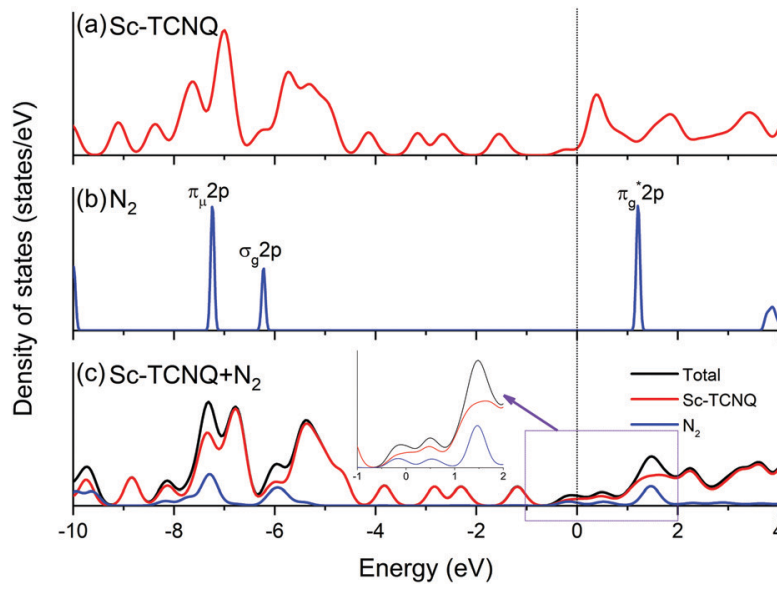

(d)

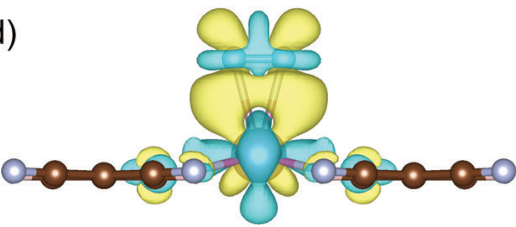

(e)

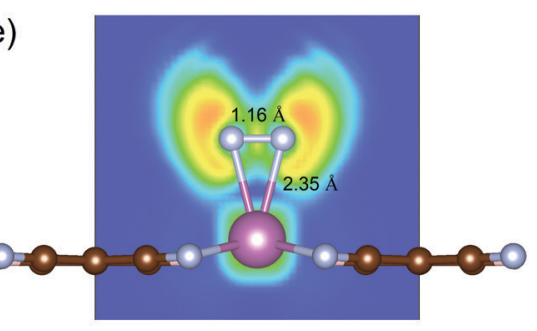

Fig. 4 Density of states of (a) pristine Sc-TCNQ, (b) $\mathrm{N}_{2}$ molecule in the gas phase, and (c) Sc-TCNQ with one adsorbed $\mathrm{N}_{2}$ molecule. Fermi level is set to zero and denoted in the black line. Inset in (c) shows the zoomed DOS near the Fermi level. (d) Charge density difference distribution (charge accumulation and depletion are shown in yellow and light blue, respectively) of $\mathrm{N}_{2}$ adsorption with the side-on configuration, and (e) corresponding ELF map with bond lengths of $\mathrm{Sc}-\mathrm{N}$ and $\mathrm{N}-\mathrm{N}$ marked in the figure. 
orbital (LUMO) and the highest occupied molecular orbital (HOMO) are respectively located at $\pi_{\mathrm{g}}{ }^{*} 2 \mathrm{p}$ and $\sigma_{\mathrm{g}} 2 \mathrm{p}$ orbitals, which are consistent with the literature. ${ }^{68}$ The $\pi_{\mathrm{g}}{ }^{*} 2 \mathrm{p}, \sigma_{\mathrm{g}} 2 \mathrm{p}$, and $\pi_{\mu} 2$ p orbitals from $\mathrm{N}_{2}$ all match with DOS for Sc-TCNQ, leading to the hybridization and delocalization of orbitals in Sc-TCNQ with $\mathrm{N}_{2}$ adsorption (Fig. 4c). This can lead to the effective activation of $\mathrm{N}_{2}$ on the catalyst, which can be confirmed by the fact that the $\mathrm{N}-\mathrm{N}$ bond is elongated from $1.098 \AA$ (in gas phase $\mathrm{N}_{2}$ ) to $1.16 \AA$ (in the adsorbed state).

$\mathrm{Sc}, \mathrm{Ti}$, and $\mathrm{V}$ are all early transition metal atoms with both occupied and unoccupied d orbitals, and the corresponding TM-based catalysts are promising for the NRR because of the 'acceptance-donation' mechanism. ${ }^{60,69}$ Unoccupied TM d orbitals can accept lone-pair electrons from $\mathrm{N}_{2}$, and in the meantime, the occupied TM d electrons can be donated to the antibonding orbitals of $\mathrm{N}_{2}$, leading to the strong binding with $\mathrm{N}_{2}$. To unravel the electron transfer during the adsorption of $\mathrm{N}_{2}$, we calculate the charge density difference distribution as $\Delta \rho=\rho\left(\right.$ Sc-TCNQ $\left.+\mathrm{N}_{2}\right)-\rho($ Sc-TCNQ $)-\rho\left(\mathrm{N}_{2}\right)$, where $\rho$ denotes the charge density distribution. Results in Fig. 4d exhibit that significant two-way charge transfer including charge accumulation (yellow) and depletion (light blue) happen around the adsorbed $\mathrm{N}_{2}$ and Sc atoms (active site for the NRR), respectively, confirming that the 'acceptance-donation' process happens in Sc-TCNQ. Charge transfer is also validated by Bader charge analysis result that Sc-TCNQ transfers $0.32 \mathrm{e}^{-}$to the adsorbed $\mathrm{N}_{2}$ molecule. From zoomed DOS near the Fermi level in Fig. 4c, the broadened and partially filled $\pi_{\mathrm{g}}{ }^{*} 2 \mathrm{p}$ can be observed, which can be attributed to the electron donation process. In addition, the ELF map (Fig. 4e) shows that ionic bonds form between Sc and the adsorbed $\mathrm{N}$.

\subsection{Gibbs free energy diagrams and NRR reaction pathways}

To gain a deeper view of the most probable NRR reaction pathway, we perform calculations on the intermediate in each step (Tables S3-S6, ESI $\dagger$ ) to obtain the Gibbs free energy diagram for the NRR. Here we only focus on the enzymatic, consecutive, and the mixed mechanism (Fig. 2) for Sc-, Ti-, and V-TCNQ after the two-step screening process discussed above (Fig. 3) and the result is shown in Fig. 5. The DFT-optimized structures for the relevant intermediates for Sc- and Ti-TCNQ are plotted in Fig. S5 (ESI $\dagger$ ) as examples. In the calculations, six consecutive protonation steps are considered, and two ammonia molecules are formed with the general formula of $\mathrm{N}_{2}+6\left(\mathrm{H}^{+}+\mathrm{e}^{-}\right) \rightarrow 2 \mathrm{NH}_{3}$.

For the first hydrogenation step ${ }^{*} \mathrm{~N} \equiv \mathrm{N}^{*} \rightarrow{ }^{*} \mathrm{~N}=\mathrm{NH}^{*}$, all three systems undergo a Gibbs free energy uphill of $0.43,0.47$, and $0.81 \mathrm{eV}$ for Sc-TCNQ, Ti-TCNQ, and V-TCNQ, respectively, and the $\mathrm{N}-\mathrm{N}$ bonds are elongated from $1.16,1.17$, and $1.17 \AA$ in ${ }^{*} \mathrm{~N} \equiv \mathrm{N}^{*}$ to $1.24,1.24$, and $1.23 \AA$ in ${ }^{*} \mathrm{~N}=\mathrm{NH}^{*}$, respectively. The comparison of Gibbs free energy of ${ }^{*} \mathrm{NH}-\mathrm{NH}^{*}$ and ${ }^{*} \mathrm{~N}-\mathrm{NH}_{2}{ }^{*}$ determines whether the second step goes through the consecutive or enzymatic pathway. From Fig. 5, free energy values of ${ }^{*} \mathrm{NH}-\mathrm{NH}^{*}$ are higher than those of ${ }^{*} \mathrm{~N}-\mathrm{NH}_{2}{ }^{*}$ for all systems, and ${ }^{*} \mathrm{~N}=\mathrm{NH}^{*} \rightarrow{ }^{*} \mathrm{~N}-\mathrm{NH}_{2}{ }^{*}$ is an exothermic step. The $\mathrm{N}-\mathrm{N}$ bond length is further elongated to over $1.4 \AA$ A. Different preferable
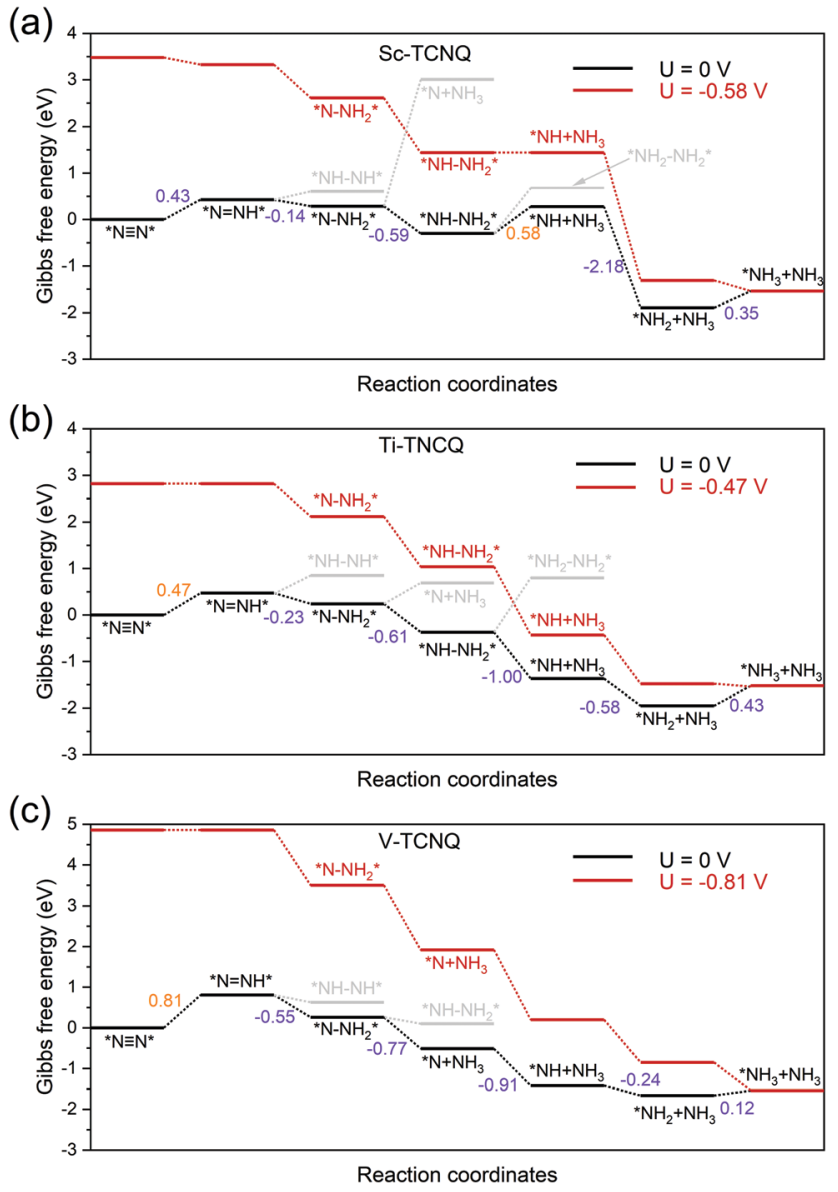

Fig. 5 Gibbs free energy diagram for the NRR through the enzymatic/ consecutive/mixed mechanism on (a) Sc-TCNQ, (b) Ti-TCNQ, and (c) $\mathrm{V}-\mathrm{TCNQ}$ at zero and applied potential $U$. For $U=0$, reaction pathways and intermediates with unfavorable Gibbs free energy change are marked in grey, and the Gibbs free energy changes for each step are marked and shown in $\mathrm{eV}$ (value marked in orange color denotes the potential limiting step).

pathways occur in the third step, where Sc- and Ti-TCNQ prefer ${ }^{*} \mathrm{~N}-\mathrm{NH}_{2}{ }^{*} \rightarrow{ }^{*} \mathrm{NH}-\mathrm{NH}_{2}{ }^{*}$ and V-TCNQ prefers ${ }^{*} \mathrm{~N}-\mathrm{NH}_{2}{ }^{*} \rightarrow$ ${ }^{*} \mathrm{~N}+\mathrm{NH}_{3}$ (one ammonia molecule released), but the step is still spontaneous. In the fourth protonation step, Sc- and Ti-TCNQ tend to disengage one $\mathrm{NH}_{3}$ molecule and form ${ }^{*} \mathrm{NH}$. There is an energy uphill for Sc-TCNQ by $0.58 \mathrm{eV}$, while for Ti- and V-TCNQ, the fourth step is exothermic. The following two steps are ${ }^{*} \mathrm{NH} \rightarrow{ }^{*} \mathrm{NH}_{2} \rightarrow{ }^{*} \mathrm{NH}_{3}$ and only the last step is endothermic with an energy change of $0.35,0.43$, and $0.12 \mathrm{eV}$ for Sc-, Ti-, and V-TCNQ, respectively. The energetically favorable pathway for Sc- and Ti-TCNQ is an enzymatic-consecutive mixed pathway, while for V-TCNQ, the consecutive pathway is adopted.

The potential-limiting step (PLS) is defined as the reaction step with the highest Gibbs free energy increase and PLS determines the performance of the electrocatalysts. From Fig. 5, we can conclude that the PLS for Ti- and V-TCNQ is the first protonation step ${ }^{*} \mathrm{~N} \equiv \mathrm{N}^{*} \rightarrow{ }^{*} \mathrm{~N}=\mathrm{NH}^{*}$ with 0.47 and $0.81 \mathrm{eV}$ free energy change, and for Sc-TCNQ, the fourth step ${ }^{*} \mathrm{NH}-\mathrm{NH}_{2}{ }^{*} \rightarrow{ }^{*} \mathrm{NH}+\mathrm{NH}_{3}$ is the PLS $(0.58 \mathrm{eV})$. With a limiting potential of $U=-0.58,-0.47$, and $-0.81 \mathrm{~V}$ for Sc-, Ti-, and 
(a)

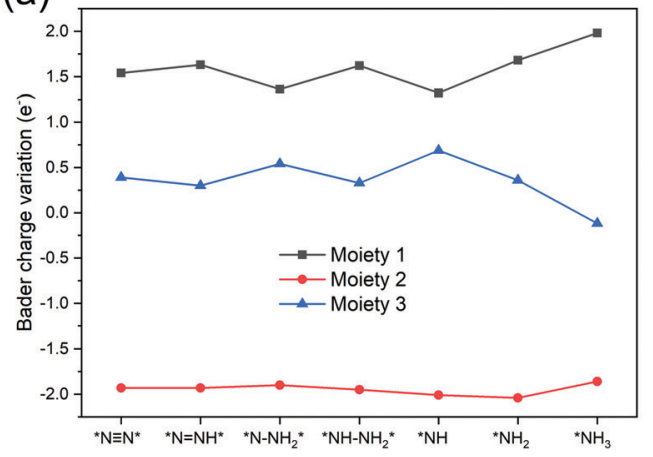

(b)

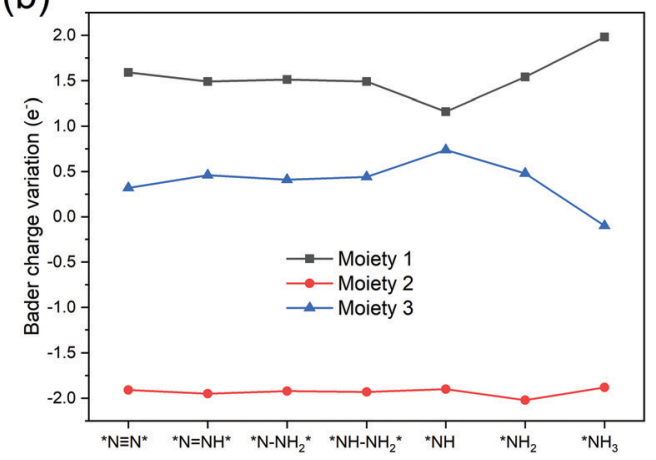

Fig. 6 Bader charge variation of the three moieties along the most favorable NRR pathway for (a) Sc-TCNQ, and (b) Ti-TCNQ.

V-TCNQ, respectively, all reaction pathways can be exothermic (Fig. 5). In addition, by comparing the Gibbs free energy change values for the PLS and those for $\mathrm{NH}_{3}$ desorption (Fig. S6, ESI $\dagger$ ), we can conclude that the as-obtained PLS rather than the $\mathrm{NH}_{3}$ desorption determines the energy barrier due to the higher $\Delta G$ values. Usually, overpotential $(\eta)$ is an indicator for determining the catalytic activity, and $\eta$ for the NRR is defined as $\eta=U_{\text {equilibrium }}-U_{\text {limiting }},{ }^{25}$ and $U_{\text {equilibrium }}$ is calculated to be $-0.25 \mathrm{~V}$ in this work (Gibbs free energy change for the total reaction). Therefore, $\eta$ values for Sc-TCNQ, Ti-TCNQ, and V-TCNQ are $0.33 \mathrm{~V}, 0.22 \mathrm{~V}$, and $0.56 \mathrm{~V}$, respectively. The overpotential values for Sc- and Ti-TCNQ are much lower than the majority of reported NRR SACs, such as Mo on nitrogen doped graphene $\left(\mathrm{N}_{3}-\mathrm{G}\right)(0.34 \mathrm{~V}),{ }^{26}$ Mo on the graphene-boron nitride hybrid sheet $(0.42 \mathrm{~V}),{ }^{70}$ and $\mathrm{Fe}$ on $\mathrm{MoN}_{2}(0.47 \mathrm{~V}){ }^{71}$ indicating that Sc-TCNQ and Ti-TCNQ are outstanding electrocatalysts for the NRR.

To further understand the NRR catalytic activity of TM-TCNQ, we perform Bader charge analysis along the most favorable reaction pathway, and each intermediate is divided into three moieties: the TCNQ nanosheet (denoted as moiety 1), single TM atom (denoted as moiety 2), and the adsorbed $\mathrm{N}_{\mathrm{x}} \mathrm{H}_{\mathrm{y}}$ (moiety 3 ). Results for Sc- and Ti-TCNQ are plotted in Fig. 6 . We can see that for all three moieties, there is obvious charge fluctuation, but generally, the TCNQ nanosheet acts as an electron acceptor, receiving about $1.5 \mathrm{e}^{-}$for each step while the TM atom donates approximately $2.0 \mathrm{e}^{-}$. Nevertheless, the fluctuation of Bader charge for the TM is very small, indicating that the TM atom also acts as a transmitter to the charge transfer between the TCNQ nanosheet and the $\mathrm{N}_{x} \mathrm{H}_{y}$ moiety.

Since the hydrogen evolution reaction (HER) is the major competing reaction for the NRR, ${ }^{72}$ we also compare the adsorption Gibbs free energy of $\mathrm{N}_{2}$ and $\mathrm{H}$ for Sc-, Ti-, and V-TCNQ. The results shown in Fig. S7 (ESI $\dagger$ ) indicate that the adsorption of $\mathrm{N}_{2}$ is more energetically favorable than $\mathrm{H}$, ensuring the selectivity of the NRR over the HER. ${ }^{27}$ Note that the difference between $\Delta G\left(\mathrm{~N}_{2}\right)$ and $\Delta G(\mathrm{H})$ is slightly larger for Sc-TCNQ than that for Ti-TCNQ and V-TCNQ, indicating that Sc-TCNQ has relatively higher selectivity.

\subsection{Stability of TM-TCNQ monolayers $(\mathrm{TM}=\mathrm{Sc}$ and Ti)}

In the final part, we test the stability of Sc- and Ti-TCNQ, which are all good candidates for NRR electrocatalysts. First, to confirm that single metal aggregation will not occur on the surface of TCNQ, we compare the binding energy $\left(E_{\mathrm{b}}\right)$ of the single atom and the cohesive energy $\left(E_{\mathrm{c}}\right)$ for metal aggregation, which are defined as $E_{\mathrm{b}}=E_{\mathrm{TM}-\mathrm{TNCQ}}-E_{\mathrm{TNCQ}}-E_{\mathrm{TM}}$ and $E_{\mathrm{c}}=\left(E_{\mathrm{TM}-\mathrm{bulk}}-n E_{\mathrm{TM}}\right) / n$, respectively, where $E_{\mathrm{TM}}$ and $E_{\mathrm{TM} \text {-bulk }}$ represent the energy of single transition metal atom and total energy of transition metals in the most stable crystal form,
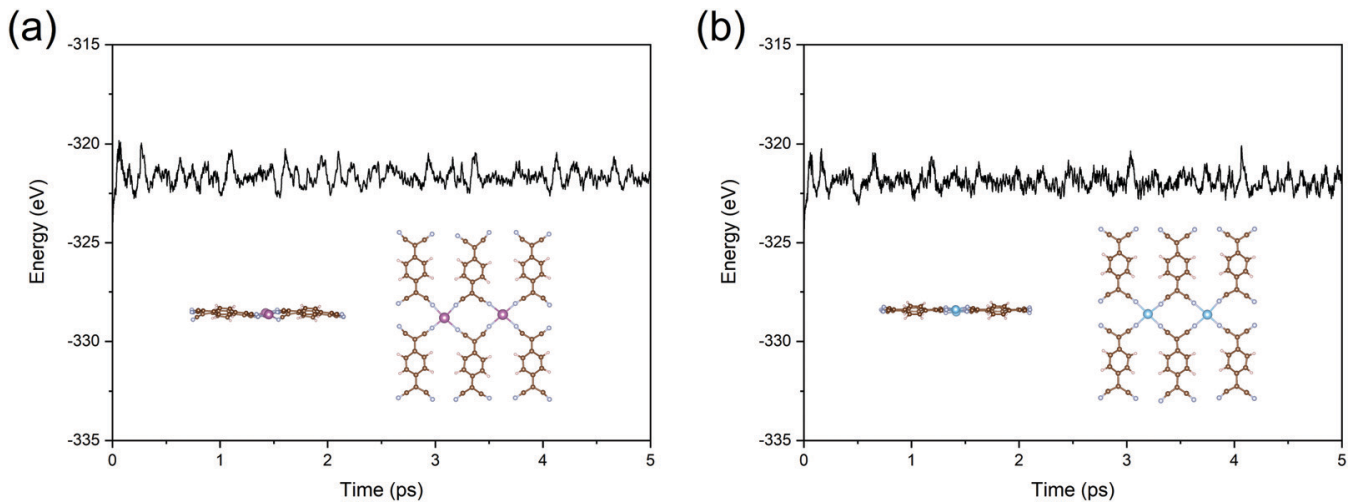

Fig. 7 Total energy as a function of time during the AIMD simulations for (a) Sc-TCNQ and (b) Ti-TCNQ. Inset shows the side and top view of the structures after 5 ps AIMD simulations, where $\mathrm{C}, \mathrm{N}, \mathrm{H}, \mathrm{Sc}$, and Ti are represented in brown, cyan, pale pink, purple, and blue, respectively. 
respectively, while $n$ denotes the number of metal atoms per unit cell of the crystal. $E_{\mathrm{b}}$ values are calculated to be -9.29 and $-9.98 \mathrm{eV}$ for $\mathrm{Sc}$ and $\mathrm{Ti}$ on TCNQ, respectively, while the $E_{\mathrm{c}}$ values are -4.59 and $-6.76 \mathrm{eV}$, respectively, indicating that binding to the substrate is more energetically favorable than aggregating into clusters for both $\mathrm{Sc}$ and $\mathrm{Ti}$ and the single atoms can be stably deposited onto the substrate as active sites.

To ensure the thermal stability of the SACs, we further perform AIMD simulations at $500 \mathrm{~K}$ and plot the total energy as a function of simulation time for Sc- and Ti-TCNQ. Results in Fig. 7 exhibit that the total energy of Sc- and Ti-TCNQ quickly converges and oscillates around the equilibrium. The structures after 5 ps AIMD simulations (insets in Fig. 7a and b) do not show an obvious structural reconstruction, and after geometric relaxation, the structures can recover again. These evidences clearly demonstrate that Sc- and Ti-TCNQ are thermally stable with a temperature up to $500 \mathrm{~K}$.

\section{Conclusions}

In this work, by means of first-principles calculations, we have systematically studied the potential application of TM-TCNQ, a group of novel single-atom catalysts, in the electrocatalytic NRR. By using a two-step screening process, we have identified three systems-Sc-, Ti-, and V-TCNQ with side-on $\mathrm{N}_{2}$ adsorption patterns-from 34 structures. $\mathrm{N}_{2}$ adsorption and activation were ensured by the unique electronic properties of TM-TCNQ and the 'acceptance-donation' mechanism. Gibbs free energy calculations proved that NRR Sc- and Ti-TCNQ were thermodynamically favorable with low overpotential values of 0.33 and $0.22 \mathrm{~V}$ through the enzymatic-consecutive mixed pathway. In addition, the NRR selectivity and stability of the catalysts were also confirmed. Overall, this work provides evidence that Sc- and Ti-TCNQ can be promising NRR electrocatalysts. The findings and methodology in this work may be extended to the design of other single-atom catalysts.

\section{Conflicts of interest}

The authors declare no competing financial interest.

\section{Acknowledgements}

This work was supported by the Research Grants Council of the Hong Kong Special Administrative Region, China (Project No. PolyU152140/19E), the Hong Kong Polytechnic University (Project No. Q54V and RH9G), the National Natural Science Foundation of China (No. 11804286), the Fundamental Research Funds for the Central Universities (Grant No. 19lgpy263), and the Scientific and Technical Innovation Action Plan (Hong Kong, Macao and Taiwan Science \& Technology Cooperation Project of Shanghai Science and Technology Committee: 19160760600). The DFT calculations were partially performed on Apollo cluster at the Department of Applied Physics, the Hong Kong Polytechnic University.

\section{References}

1 V. Smil, Enriching the earth: Fritz Haber, Carl Bosch, and the transformation of world food production, MIT press, 2004.

2 J. N. Galloway, A. R. Townsend, J. W. Erisman, M. Bekunda, Z. Cai, J. R. Freney, L. A. Martinelli, S. P. Seitzinger and M. A. Sutton, Science, 2008, 320, 889-892.

3 C. Zamfirescu and I. Dincer, J. Power Sources, 2008, 185, 459-465.

4 D. Bernhardt and J. Reilly II, Mineral Commodity Summaries 2019, Department of the Interior (DOI), US Geological Survey, Reston, USA, 2019.

5 C. J. van der Ham, M. T. Koper and D. G. Hetterscheid, Chem. Soc. Rev., 2014, 43, 5183-5191.

6 M. A. Shipman and M. D. Symes, Catal. Today, 2017, 286, 57-68.

7 X. Cui, C. Tang and Q. Zhang, Adv. Energy Mater., 2018, 8, 1800369.

8 S. L. Foster, S. I. P. Bakovic, R. D. Duda, S. Maheshwari, R. D. Milton, S. D. Minteer, M. J. Janik, J. N. Renner and L. F. Greenlee, Nat. Catal., 2018, 1, 490-500.

9 W. Guo, K. Zhang, Z. Liang, R. Zou and Q. Xu, Chem. Soc. Rev., 2019, 48, 5658-5716.

10 A. J. Martín, T. Shinagawa and J. Pérez-Ramírez, Chem, 2019, 5, 263-283.

11 C. Guo, J. Ran, A. Vasileff and S.-Z. Qiao, Energy Environ. Sci., 2018, 11, 45-56.

12 J. H. Montoya, C. Tsai, A. Vojvodic and J. K. Norskov, ChemSusChem, 2015, 8, 2180-2186.

13 E. Skúlason, T. Bligaard, S. Gudmundsdóttir, F. Studt, J. Rossmeisl, F. Abild-Pedersen, T. Vegge, H. Jónsson and J. K. Nørskov, Phys. Chem. Chem. Phys., 2012, 14, 1235-1245.

14 J. G. Howalt, T. Bligaard, J. Rossmeisl and T. Vegge, Phys. Chem. Chem. Phys., 2013, 15, 7785-7795.

15 Á. B. Höskuldsson, Y. Abghoui, A. B. Gunnarsdóttir and E. Skúlason, ACS Sustainable Chem. Eng., 2017, 5, 10327-10333.

16 Y. Abghoui, A. L. Garden, J. G. Howalt, T. Vegge and E. Skúlason, ACS Catal., 2015, 6, 635-646.

17 L. M. Azofra, N. Li, D. R. MacFarlane and C. Sun, Energy Environ. Sci., 2016, 9, 2545-2549.

18 Y. Ying, K. Fan, X. Luo and H. Huang, J. Mater. Chem. A, 2019, 7, 11444-11451.

19 X. Li, X. Yang, Y. Huang, T. Zhang and B. Liu, Adv. Mater., 2019, 31, 1902031.

20 H. Jin, C. Guo, X. Liu, J. Liu, A. Vasileff, Y. Jiao, Y. Zheng and S. Z. Qiao, Chem. Rev., 2018, 118, 6337-6408.

21 L. M. Yang, V. Bacic, I. A. Popov, A. I. Boldyrev, T. Heine, T. Frauenheim and E. Ganz, J. Am. Chem. Soc., 2015, 137, 2757-2762.

22 B. Song, Y. Zhou, H. M. Yang, J. H. Liao, L. M. Yang, X. B. Yang and E. Ganz, J. Am. Chem. Soc., 2019, 141, 3630-3640.

23 J.-H. Liu, L.-M. Yang and E. Ganz, J. Mater. Chem. A, 2019, 7, 11944-11952.

24 Y. Ying, K. Fan, S. Zhu, X. Luo and H. Huang, J. Phys. Chem. C, 2020, 124, 639-646. 
25 J. Zhao and Z. Chen, J. Am. Chem. Soc., 2017, 139, 12480-12487.

26 W. Zhao, L. Zhang, Q. Luo, Z. Hu, W. Zhang, S. Smith and J. Yang, ACS Catal., 2019, 9, 3419-3425.

27 C. Ling, Y. Ouyang, Q. Li, X. Bai, X. Mao, A. Du and J. Wang, Small Methods, 2018, 3, 1800376.

28 X. Chen, X. Zhao, Z. Kong, W.-J. Ong and N. Li, J. Mater. Chem. A, 2018, 6, 21941-21948.

29 Z. Chen, J. Zhao, C. R. Cabrera and Z. Chen, Small Methods, 2018, 3, 1800368.

30 H. Yin, S.-L. Li, L.-Y. Gan and P. Wang, J. Mater. Chem. A, 2019, 7, 11908-11914.

31 L. M. Azofra, C. Sun, L. Cavallo and D. R. MacFarlane, Chem. - Eur. J., 2017, 23, 8275-8279.

32 T. Yang, T. T. Song, S. Wang, D. Chi, L. Shen, M. Yang and Y. P. Feng, Nano Energy, 2020, 68, 104304.

33 Z. Geng, Y. Liu, X. Kong, P. Li, K. Li, Z. Liu, J. Du, M. Shu, R. Si and J. Zeng, Adv. Mater., 2018, 30, 1803498.

34 L. Han, X. Liu, J. Chen, R. Lin, H. Liu, F. Lu, S. Bak, Z. Liang, S. Zhao, E. Stavitski, J. Luo, R. R. Adzic and H. L. Xin, Angew. Chem., Int. Ed., 2019, 58, 2321-2325.

35 H. Tao, C. Choi, L.-X. Ding, Z. Jiang, Z. Han, M. Jia, Q. Fan, Y. Gao, H. Wang, A. W. Robertson, S. Hong, Y. Jung, S. Liu and Z. Sun, Chem, 2019, 5, 204-214.

36 F. Lü, S. Zhao, R. Guo, J. He, X. Peng, H. Bao, J. Fu, L. Han, G. Qi, J. Luo, X. Tang and X. Liu, Nano Energy, 2019, 61, 420-427.

37 M. Yoon, R. Srirambalaji and K. Kim, Chem. Rev., 2011, 112, 1196-1231.

38 X. L. Wang, L. Z. Dong, M. Qiao, Y. J. Tang, J. Liu, Y. Li, S. L. Li, J. X. Su and Y. Q. Lan, Angew. Chem., Int. Ed., 2018, 57, 9660-9664.

39 Q. Cui, G. Qin, W. Wang, K. R. Geethalakshmi, A. Du and Q. Sun, J. Mater. Chem. A, 2019, 7, 14510-14518.

40 X. Shi, C. Lin, C. Minot, T.-C. Tseng, S. L. Tait, N. Lin, R. Zhang, K. Kern, J. Cerdá and M. A. Van Hove, J. Phys. Chem. C, 2010, 114, 17197-17204.

41 T.-C. Tseng, N. Abdurakhmanova, S. Stepanow and K. Kern, J. Phys. Chem. C, 2011, 115, 10211-10217.

42 N. Abdurakhmanova, T.-C. Tseng, A. Langner, C. Kley, V. Sessi, S. Stepanow and K. Kern, Phys. Rev. Lett., 2013, 110, 027202.

43 Q. Deng, J. Zhao, T. Wu, G. Chen, H. A. Hansen and T. Vegge, J. Catal., 2019, 370, 378-384.

44 N. Wang, L. Feng, Y. Shang, J. Zhao, Q. Cai and P. Jin, RSC $A d v .$, 2016, 6, 72952-72958.

45 Q. Deng, T. Wu, G. Chen, H. A. Hansen and T. Vegge, Phys. Chem. Chem. Phys., 2018, 20, 5173-5179.

46 J.-H. Liu, L.-M. Yang and E. Ganz, J. Mater. Chem. A, 2019, 7, 3805-3814.

47 G. Kresse and J. Furthmüller, Phys. Rev. B: Condens. Matter Mater. Phys., 1996, 54, 11169.
48 G. Kresse and D. Joubert, Phys. Rev. B: Condens. Matter Mater. Phys., 1999, 59, 1758.

49 J. P. Perdew, K. Burke and M. Ernzerhof, Phys. Rev. Lett., 1996, 77, 3865.

50 S. Grimme, J. Antony, S. Ehrlich and H. Krieg, J. Chem. Phys., 2010, 132, 154104.

51 W. Tang, E. Sanville and G. Henkelman, J. Phys.: Condens. Matter, 2009, 21, 084204.

52 S. Nosé, J. Chem. Phys., 1984, 81, 511-519.

53 W. G. Hoover, Phys. Rev. A: At., Mol., Opt. Phys., 1985, 31, 1695-1697.

54 G. Henkelman, B. P. Uberuaga and H. Jónsson, J. Chem. Phys., 2000, 113, 9901-9904.

55 K. Momma and F. Izumi, J. Appl. Crystallogr., 2011, 44, 1272-1276.

56 V. Wang, N. Xu, J.-C. Liu, G. Tang and W. Geng, 2019, arXiv preprint arXiv:1908.08269.

57 A. A. Peterson, F. Abild-Pedersen, F. Studt, J. Rossmeisl and J. K. Nørskov, Energy Environ. Sci., 2010, 3, 1311-1315.

58 J. K. Nørskov, J. Rossmeisl, A. Logadottir, L. Lindqvist, J. R. Kitchin, T. Bligaard and H. Jonsson, J. Phys. Chem. B, 2004, 108, 17886-17892.

59 P. W. Atkins, Atkins' physical chemistry, Oxford University Press, Oxford, 11th edn, 2018.

60 C. Ling, X. Niu, Q. Li, A. Du and J. Wang, J. Am. Chem. Soc., 2018, 140, 14161-14168.

61 S. Zhang, Q. Wang, Y. Kawazoe and P. Jena, J. Am. Chem. Soc., 2013, 135, 18216-18221.

62 T. Yu, Z. Zhao, L. Liu, S. Zhang, H. Xu and G. Yang, J. Am. Chem. Soc., 2018, 140, 5962-5968.

63 X. F. Li, Q. K. Li, J. Cheng, L. Liu, Q. Yan, Y. Wu, X. H. Zhang, Z. Y. Wang, Q. Qiu and Y. Luo, J. Am. Chem. Soc., 2016, 138, 8706-8709.

64 C. Liu, Q. Li, J. Zhang, Y. Jin, D. R. MacFarlane and C. Sun, J. Mater. Chem. A, 2019, 7, 4771-4776.

65 B. Huang, N. Li, W.-J. Ong and N. Zhou, J. Mater. Chem. A, 2019, 7, 27620-27631.

66 L. Li, B. Li, Q. Guo and B. Li, J. Phys. Chem. C, 2019, 123, 14501-14507.

67 C. Ling, X. Bai, Y. Ouyang, A. Du and J. Wang, J. Phys. Chem. $C, 2018,122,16842-16847$.

68 J. C. Liu, X. L. Ma, Y. Li, Y. G. Wang, H. Xiao and J. Li, Nat. Commun., 2018, 9, 1610.

69 M.-A. Légaré, G. Bélanger-Chabot, R. D. Dewhurst, E. Welz, I. Krummenacher, B. Engels and H. Braunschweig, Science, 2018, 359, 896-900.

70 Y. Huang, T. Yang, L. Yang, R. Liu, G. Zhang, J. Jiang, Y. Luo, P. Lian and S. Tang, J. Mater. Chem. A, 2019, 7, 15173-15180.

71 Q. Li, L. He, C. Sun and X. Zhang, J. Phys. Chem. C, 2017, 121, 27563-27568.

72 Z. W. Seh, J. Kibsgaard, C. F. Dickens, I. Chorkendorff, J. K. Norskov and T. F. Jaramillo, Science, 2017, 355, eaad4998. 